\title{
Sensor Ketinggian Air Menggunakan Concentric Bundle Probe
}

\begin{tabular}{l}
\hline Received \\
9 Desember 2017 \\
Revised \\
10 Januari 2018 \\
Accepted for Publication \\
19 Pebruari 2018 \\
Published \\
19 Pebruari 2018 \\
\hline
\end{tabular}

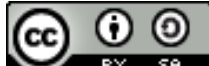

This work is licensed under a Creative Commons Attribution ShareAlike 4.0 International License.

\author{
Samian $^{1^{*}}$, A. H. Zaidan ${ }^{1}$ \\ ${ }^{1}$ Departemen Fisika, Fakultas Sains dan Teknologi, Universitas Airlangga Surabaya \\ *E-mail: samian@ fst.unair.ac.id
}

\begin{abstract}
Concentric bundled probe can be utilized to detect liquid level based on displacement sensor. The working mechanism of the sensor is detecting reflector displacement which attached on membrane due to level liquid changes. Reflector displacement can be detected on reflection of light intensity changes from incoming reflector to receiver fiber. The receiver fibers are surrounding its transmitter fiber. The using of one layer of membrane of nitrile polymer with $0.08 \mathrm{~mm}$ thickness produce the linear region of $100 \mathrm{~cm}$ with $0,9 \mathrm{~cm}$ resolution.
\end{abstract}

Keyword: water level sensor, concentric bundle probe, displacement sensor

\begin{abstract}
Abstrak
Concentric bundle probe dapat dimanfaatkan untuk mendeteksi ketinggian air dengan berbasis pada sensor pergeseran. Mekanisme kerja sensor adalah mendeteksi pergeseran reflektor yang merekat pada membran akibat perubahan ketinggian zat cair. Pergeseran reflektor terdeteksi melalui perubahan intensitas cahaya pantulan dari reflektor yang masuk fiber optik penerima yang mengelilingi fiber optik pemancar cahaya. Penggunaan satu lapis membran dari bahan nitrile polymer dengan tebal $0,08 \mathrm{~mm}$ menghasilkan daerah kerja sensor sebesar $100 \mathrm{~cm}$ dengan resolusi sebesar $0,9 \mathrm{~cm}$.
\end{abstract}

Kata Kunci: sensor ketinggian air, concentric bundle probe, sensor pergeseran.

\section{Pendahuluan}

Penggunaan bahan magnetik dalam bentuk cair/koloid (ferrofluid) Penelitian tentang aplikasi fiber optik sebagai sensor ketinggian zat cair telah banyak dilakukan, baik ragam maupun konfigurasinya. Penggunaan fiber optik dari bahan plastik yang dipoles bagian claddingnya telah digunakan untuk mendeteksi ketinggian zat cair secara diskontinyu [1]. Fiber optik yang dipoles dilengkungkan seperti huruf $U$ dan berfungsi sebagai saklar yang diletakkan pada beberapa ketinggian dalam tangki zat cair. Deteksi ketinggian zat cair juga dapat dilakukan menggunakan sepasang fiber optik yang letaknya berdampingan (fiber bundle dengan tipe probe sepasang fiber optik) dan dihubungkan dengan elemen transparan berbentuk kerucut [2] dan prisma [3,4]. Sistem deteksi didasarkan pada perubahan intensitas cahaya yang mengalami pemantulan dari dalam probe ketika probe tersebut bersentuan dengan zat cair. Perubahan intensitas cahaya tersebut kemudian diterima oleh salah satu fiber pada fiber bundle. Pembacaan ketinggian zat cair dilakukan dengan menggerakkan probe untuk menemukan keberadaan zat cair. Teknik lain dalam mendeteksi ketinggian zat cair dilakukan menggunakan fiber Bragg grating [5] tipe tapered chirped [6] dan long periode [7] yang terhubung dengan pelampung. Pada teknik ini, perubahan ketinggian zat akan diikuti oleh perubahan kedudukan pelampung yang akan mengubah periode kisi. Perubahan periode kisi tersebut terbaca melalui perubahan panjang gelombang Bragg pantulan dari kisi. Sistem yang lain dalam mendeteksi ketinggian zat cair adalah menggunakan fiber coupler [8]. Sistem ini prinsip kerjanya berdasarkan sensor pergeseran menggunakan fiber coupler. Pergeseran reflektor yang direkatkan pada membran akan terjadi akibat perubahan ketinggian zat cair (perubahan tekanan hidrostatis). Pergeseraan reflektor tersebut akan mengubah intensitas cahaya pantulan dari reflektor yang diterima oleh salah satu kanal keluaran fiber coupler. 
Fiber bundle merupakan perangkat optik yang terbuat dari fiber optik. Berdasarkan fungsinya sebagai sensor, fiber bundle digolongkan menjadi dua jenis yaitu fiber bundle dengan probe terdiri dari sepasangan fiber optik (a pair bundle probe) dan lebih dari dua buah fiber optik dengan dengan konfigurasi sebuah fiber optik berada di tengah, fiber optik lainnya mengelilingi (concentric bundle probe). Biasanya fiber optik yang berada di tengah difungsikan sebagai pemancar cahaya dan yang lainnya difungsikan sebagai penerima cahaya. Concentric bundle probe telah mampu digunakan untuk mendeteksi pergeseran reflektor dengan cukup baik [9]. Berdasarkan kemampuan tersebut, dalam artikel ini akan diperlihatkan kemampuan concentric bundle probe dalam mendeteksi ketinggian zat cair, dalam hal ini zat cair yang digunakan adalah air.

\section{Desain dan Prinsip Kerja Sensor}

Desain sensor ketinggian zat cair diperlihatkan pada Gambar 1(a). Komponen-komponen sensor terdiri dari laser sebagai sumber cahaya, detektor optik, concentric bundle probe, dan tangki sebagai wadah air. Pada bagian dasar tangki terdapat perangkat pergeseran reflektor (PPR) seperti diperlihatkan pada Gambar 1(b). PPR terdiri dari reflektor (plat datar) yang direkatkan pada membrane. Reflektor akan bergeser $\left(z^{\prime}\right)$ jika terjadi perubahan tekanan hidrostatis $\left(P_{h}\right)$ akibat perubahan ketinggian zat cair $(h)$.

Mekanisme kerja sensor ketinggian zat cair adalah cahaya keluaran dari fiber pemancar akan dipantulkan oleh reflektor dan diterima oleh fiber penerima. Perubahan ketinggian zat cair mengakibatkan pergeseran reflektor, sebagai akibatnya jarak antara reflektor terhadap probe sensor (z) akan berubah. Perubahan nilai z tersebut akan mengakibatkan perubahan intensitas cahaya yang diterima oleh fiber penerima dan terbaca oleh detektor optis. Dengan demikian ketinggian zat cair terdeteksi melalui perubahan intensitas cahaya yang terbaca pada detektor optis (dalam hal ini perubahan tegangan keluaran detektor).

\section{Eksperimen}

Set-up eksperimen diperlihatkan oleh Gambar 2 yang terdiri dari laser semikonduktor (panjang gelombang $630 \mathrm{~nm}$ dan daya $10 \mathrm{~mW}$ ), detektor optis (818 SL Newport), concentric bundle probe (dari bahan plastik dengan konfigurasi $1: 16$ fiber), voltmeter (digital multimeter), xyz translation stage digunakan untuk menggeser probe sensor, pompa air manual digunakan untuk memompa air ke dalam tangki, tangki berskala dari bahan akrilik (diameter $6 \mathrm{~cm}$ dan tinggi $200 \mathrm{~cm}$ ). Pada bagian dasar tangki terdapat kran yang digunakan untuk mengeluarkan air dan PPR yang terbuat dari aluminium (diameter $10 \mathrm{~mm}$ dan tebal $0,20 \mathrm{~mm}$ ) sebagai reflektor, membran (nitrile polymer) dengan tebal 0,08 $\mathrm{mm}$, dan holder membran yang terbuat dari bahan kuningan dengan diameter luar $18 \mathrm{~mm}$ dan diameter dalam $15 \mathrm{~mm}$. Reflektor direkatkan pada membran menggunakan lem epoxy. Dua jenis PPR yang digunakan dalam eksperimen yaitu PPR 1 dan PPR 2 yang masing-masing terdiri dari 1 dan 2 lapis membran.

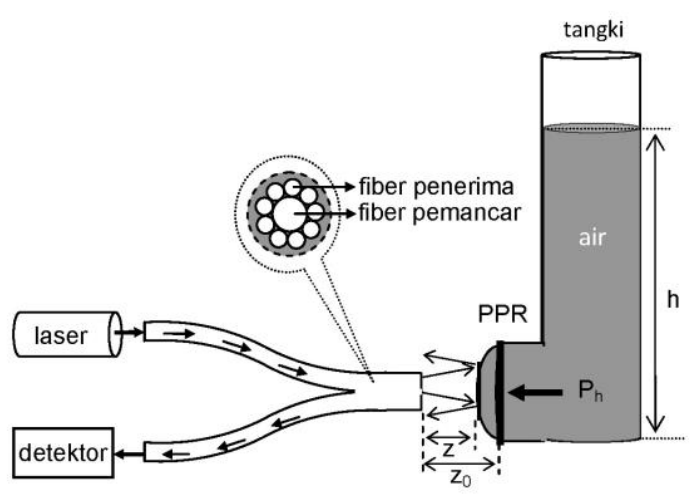

(a)

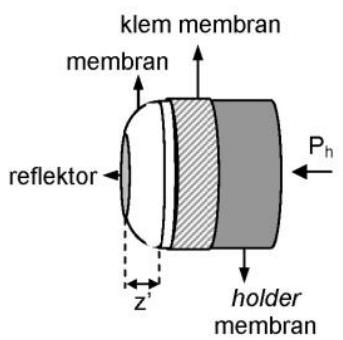

(b)

Gambar 1. Desain sensor ketinggian zat cair menggunakan concentric bundle probe. 


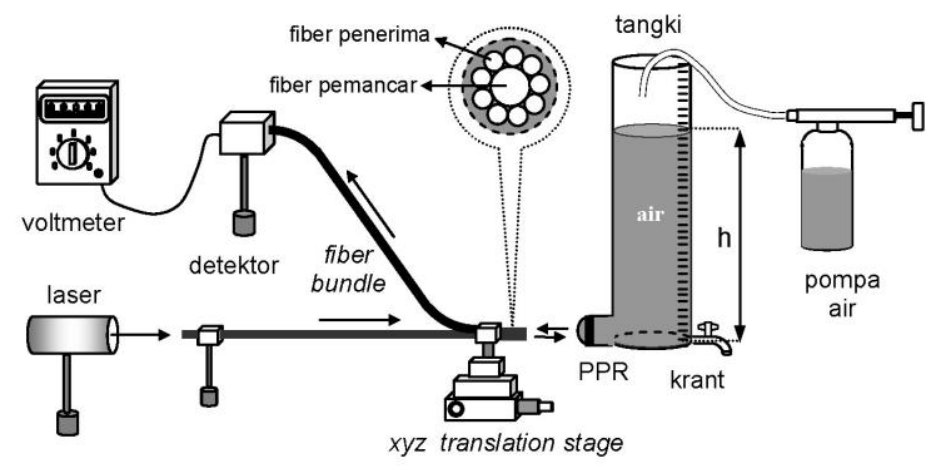

Gambar 2. Set-up eksperimen sensor ketinggian air menggunakan concentric bundle probe.

Langkah pertama eksperimen adalah mengkarakterisasi pergeseran probe sensor terhadap reflektor pada PPR. Langkah tersebut dilakukan dengan menempatkan probe sensor berada ditengahtengah dan berhimpit dengan refelktor PPR 1 saat tangki dalam keadaan kosong. Pencatatan tegangan keluaran detektor dilakukan setiap probe digeser mundur sebesar $100 \mu \mathrm{m}$. Pergeseran probe dilakukan menggunakan $x y z$ translation stage. Langkah kedua adalah mengkarakterisasi sensor ketinggian air pada proses pengosongan tangki. Langkah kedua diawali dengan mengisi tangki dengan air setinggi $150 \mathrm{~cm}$, kemudian menempatkan probe berhimpit dengan reflektor PPR $1(\mathrm{z}=0 \mathrm{~mm})$. Batas ketinggian air dipilih $150 \mathrm{~cm}$ dikarenakan kemampuan membran satu lapis menahan tekanan hidrostatis maksimal pada ketinggian tersebut (untuk tinggi air lebih dari $150 \mathrm{~cm}$, membran satu lapis dikhawatirkan mengalami deformasi). Selanjutnya, pencatatan tegangan keluaran detektor dilakukan setiap ketinggian air diturunkan sebesar $1 \mathrm{~cm}$. Setelah tangki dalam keadaan kosong, dilakukan pengukuran posisi $\mathrm{z}_{0}$, yaitu posisi probe sensor terhadap reflektor ketika tangki dalam keadaan kosong. Pengukuran dilakukan menngunakan xyz translation stage. Setelah itu, probe dikembalikan ke tempat semula $(\mathrm{z}=0 \mathrm{~mm})$. Selanjutnya dilakukan langkah ketiga yaitu karakterisasi sensor saat pengisian tangki dengan air. Langkah ketiga dilakukan dengan cara mengisi tangki dengan air menggunakan pompa. Setiap ketinggian air bertambah $1 \mathrm{~cm}$, pencatatan tegangan keluaran detektor dilakukan. Pencatatan tersebut dilakukan sampai tinggi maksimal air dalam tangki sama seperti saat proses pengosongan. Proses pengambilan data pengosongan dan pengisian tangki diulang sebanyak tiga kali. Ketiga langkah tersebut dilakukan untuk PPR 2. Karena PPR 2 tersusun atas dua lapis membran sehingga mampu menahan tekanan hidrostatis lebih besar dari pada PPR 1, maka ketinggian maksimal air yang diberlakukan dalam eksprimen menggunakan PPR 2 adalah setinggi tangki yang digunakan yaitu $200 \mathrm{~cm}$. Langkah terakhir adalah uji stabilitas sensor. Uji stabilitas sensor dilakukan dengan mengukur tegangan keluaran detektor dalam rentang waktu 30 sekon selama 720 sekon. Uji stabilitas dilakukan pada rentang daerah kerja sensor (daerah yang mana hubungan tegangan keluaran detektor linier terhadap ketinggian air) yang terbagi pada beberapa titik ketinggian air.

\section{Hasil dan Pembahasan}

Karakterisasi pergeseran probe sensor terhadap reflektor untuk PPR 1 dan PPR 2 masing-masing menghasilkan data hubungan tegangan keluaran detektor (V) terhadap pergeseran probe (z). Data tersebut diperlihatkan melalui grafik pada Gambar 3. Dari Gambar 3, tampak bahwa pola hubungan tegangan keluaran detektor terhadap pergeseran probe untuk kedua PPR hampir sama, artinya kedua PPR hampir identik. Dari grafik dapat disimpulkan bahwa terdapat dua daerah yaitu daerah dengan kemiringan positif (front slope) dan kemiringan negatif (back slope). Untuk front slope, rentangnya sebesar $1 \mathrm{~mm}$ dan sisanya $(8 \mathrm{~mm})$ merupakan rentang untuk back slope. Untuk rentang keseluruhan (0-8 $\mathrm{mm}$ ) disebut rentang dinamik (dinamic range). 


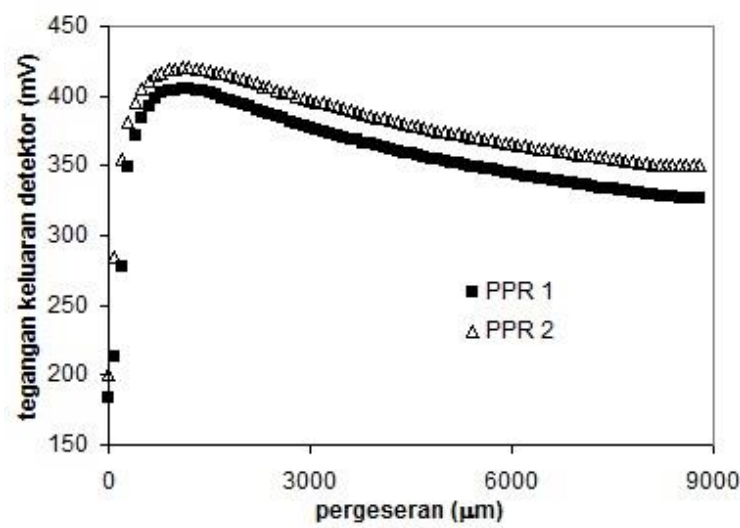

Gambar 3. Grafik karakteristik pergeseran probe sensor terhadap reflektor untuk PPR 1 dan PPR 2.

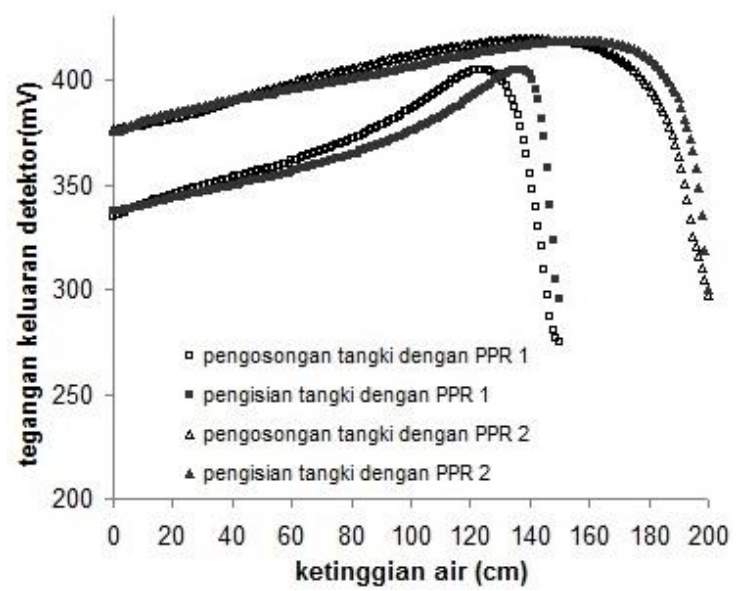

Gambar 4. Grafik hasil karakterisasi sensor ketinggian air menggunkan PPR 1 dan PPR 2 untuk proses pengosongan dan pengisian tangki air.

Karakterisasi sensor ketinggian air air untuk proses pengosongan dan pengisian tangki menghasilkan data tegangan keluaran detekktor sebagai fungsi ketinggian. Untuk kedua PPR yang digunakan, datanya diperlihatkan melalui grafik pada Gambar 4. Hasil pengukuran nilai $\mathrm{z}_{0}$ untuk sensor menggunakan PPR 1 dan PPR 2 masing-masing sebesar 7,7 $\mathrm{mm}$ dan 4,8 $\mathrm{mm}$.

Hubungan antara tegangan keluaran detektor terhadap ketinggian air berkebalikan dengan grafik hasil karakterisasi pergeseran probe. Hal tersebut terjadi karena saat ketinggian air maksimal, jarak antara probe terhadap reflektor menjadi minimal, demikian sebaliknya. Dalam rentang dinamik deteksi ketinggian air, terdapat dua titik ketinggian yang berbeda tapi mempunyai nilai tegangan keluaran detektor yang sama yaitu pada daerah front slope dan daerah back slope. Oleh karena itu tidak semua rentang dinamik dapat dapat digunakan untuk mendeteksi ketinggian air. Oleh karena itu dilakukan lagi karakterisasi sensor ketinggian air dengan ketinggian air yang dibatasi agar hanya menghasilkan daerah front slope saja. Dipilih daerah front slope saja dengan pertimbangan jangkauannya lebih besar dari pada daerah back slope. Karakterisasi dilakukan dengan jarak probe terhadap reflektor saat ketinggian air $0 \mathrm{~cm}\left(\mathrm{z}_{0}\right)$ bernilai sama seperti eksperimen pertama yaitu $7,7 \mathrm{~mm}$ untuk PPR 1 dan 4,8 mm untuk PPR 2. Batas ketinggian air maksimal diberlakukan dengan mengacu pada data pada Gambar 3. Hasil karakterisasi ulangan diperlihatkan melalui grafik pada Gambar 5. Kesalahan pengukuran pada PPR 1 rata-rata sebesar $1,2 \mathrm{mV}$ dan $0,6 \mathrm{mV}$ masing-masing untuk proses pengosongan dan pengisian tangki. Untuk PPR 2, kesalahan pengukuran rata-tata yang dihasilkan sebesar $0,5 \mathrm{mV}$ dan $0,2 \mathrm{mV}$ masing-masing untuk proses pengosongan dan pengisian tangki. Dengan mengacu pada data yang diperlihatkan melalui grafik pada Gambar 5, jangkauan sensor yang dihasilkan untuk PPR 1 dan PPR 2 masing-masing sebesar $130 \mathrm{~cm}$ dan $150 \mathrm{~cm}$. 


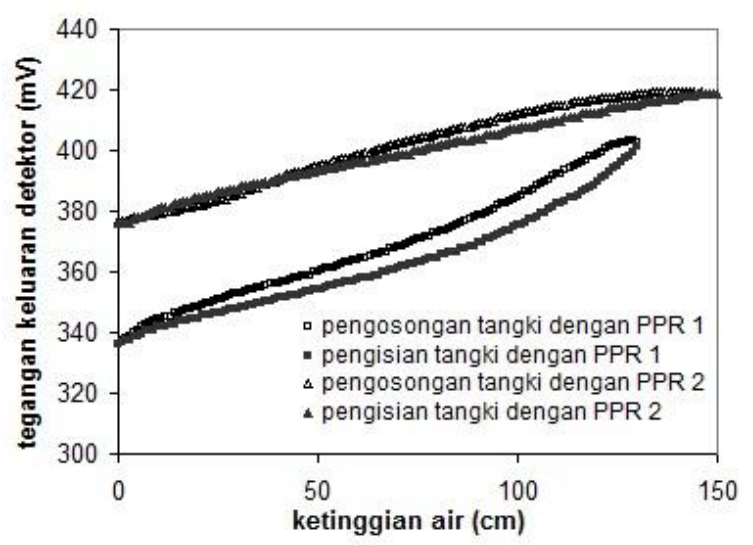

Gambar 5. Grafik hasil karakterisasi sensor ketinggian air dengan ketinggian air yang dibatasi untuk menghasilkan daerah front slope.

Hasil karakterisasi sensor memperlihatkan bahwa deteksi ketinggian air untuk proses pengosongan dan pengisian tangki (histerisis) nilainya tidak sama. Hal tersebut terjadi karena sifat relaksasi membran setelah mendapat tekanan. Semakin besar membran mendapat tekanan, semakin lama waktu relaksasinya. Beda nilai tegangan keluaran detektor pada ketinggian yang sama untuk proses pengosongan dan pengisian rata-rata sebesar 7,2 $\mathrm{mV}$ dan $8,3 \mathrm{mV}$ masing-masing untuk PPR 1 dan PPR 2.

Daerah kerja sensor merupakan daerah yang mana hubungan antara tegangan keluaran detektor (V) linier terhadap ketinggian air (h). Oleh karena itu dilakukan uji linier antara $\mathrm{V}$ terhadap $\mathrm{h}$ menggunakan program regresi linier. Hasilnya diperlihatkan pada Gambar 6. Rentang daerah linier yang dihasilkan sebesar 0-100 cm dan 0-135 cm masing-masing untuk PPR 1 dan PPR 2 dengan tingkat kelinieran lebih dari $99 \%$. Slope grafik linier yang dihasilkan merupakan nilai dari sensitivitas sensor. Dari data dalam Gambar 6, sensitivitas sensor menggunakan PPR 1 bernilai 0,43 $\mathrm{mV} / \mathrm{cm}$ dan $0,35 \mathrm{mV} / \mathrm{cm}$ masing-masing untuk proses pengosongan dan pengisian tangki. Untuk PPR 2 nilai sensitivitanya sebesar $0,34 \mathrm{mV} / \mathrm{cm}$ dan $0,29 \mathrm{mV} / \mathrm{cm}$ masing-masing untuk proses pengosongan.

Hasil uji stabilitas sensor berupa data tegangan keluaran detektor terhadap waktu yang diukur pengukuran di empat ketinggian berbeda. Data tersebut diperlihatkan melalui grafik pada Gambar 7. Nilai standart deviasi rata-rata yang dihasil untuk PPR 1 dan PPR 2 bernilai sama, yaitu sebesar 0,4 $\mathrm{mV}$. Dari nilai standart deviasi yang diperoleh, dapat ditentukan nilai resolusi sensor. Resolusi sensor ditentukan dengan cara membagi nilai standart deviasi dengan nilai sensitivitas sensor. Hasil perhitungan menunjukkan bahwa resolusi sensor bernilai $0,9 \mathrm{~cm}$ dan $1,1 \mathrm{~cm}$ masing-masing untuk proses pengosongan dan pengisian tangki untuk PPR 1 serta $1,2 \mathrm{~cm}$ dan $1,4 \mathrm{~cm}$ masing-masing untuk proses pengosongan dan pengisian tangki untuk PPR 2. Terlihat bahwa resolusi pada proses pengosongan lebih baik nilainya dari pada proses pengisian serta resolusi pada RDD 1 lebih baik nilainya dari pada RDD 2. Hal tersebut dapat dipahami karena RDD 1 (menggunkan satu lapis membran) lebih elastis daripada RDD 2 (menggunakan dua lapis membran. Secara keseluruhan, karakteristik sensor ketinggian air menggunakan concentric bundle probe diperlihatkan pada Tabel 1.

Dari nilai parameter yang tertera dalam Tabel 1, terlihat daerah kerja sensor (daerah linier) menggunakan PPR 2 lebih besar dari pada menggunakan PPR 1. Jika dilihat dari nilai sensitivitas sensor yang berimplikasi pada nilai resolusi sensor, maka kinerja sensor menggunakan PPR1 lebih baik dari pada menggunakan PPR 2. Artinya, sensor menggunkan PPR 1 lebih teliti dari pada sensor menggunakan PPR 2. Dari hasil eksperimen ini, concentric bundle probe dapat dijadikan salah satu perangkat pilihan untuk mendeteksi ketinggian air dengan karakteristik sensor seperti tertera dalam Tabel 1. Penggunaan membran berbahan nitrile polymer bahkan telah dapat digunkan untuk mendeteksi ketinggian bahan bakar berupa bensin [8]. 


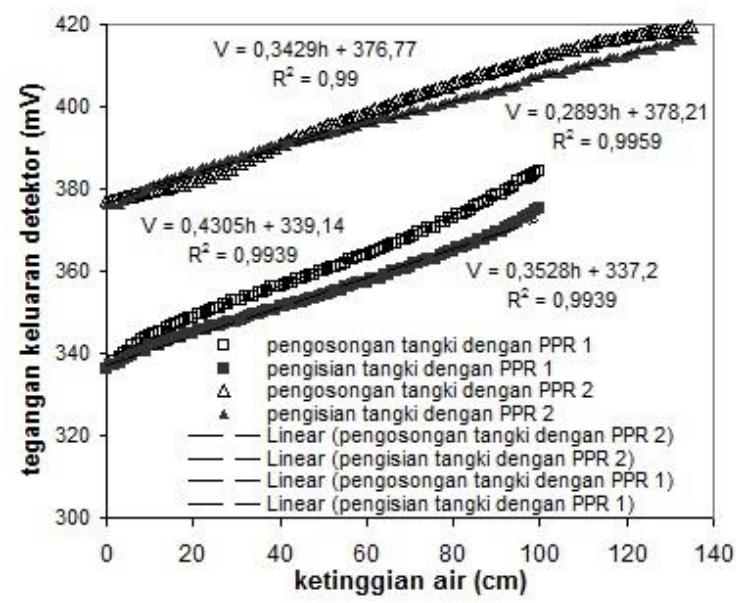

Gambar 6. Grafik hubungan linier antara tegangan keluaran detektor terhadap ketinggian air untuk proses pengosongan dan pengisian tangki untuk PPR 1 dan PPR 2.
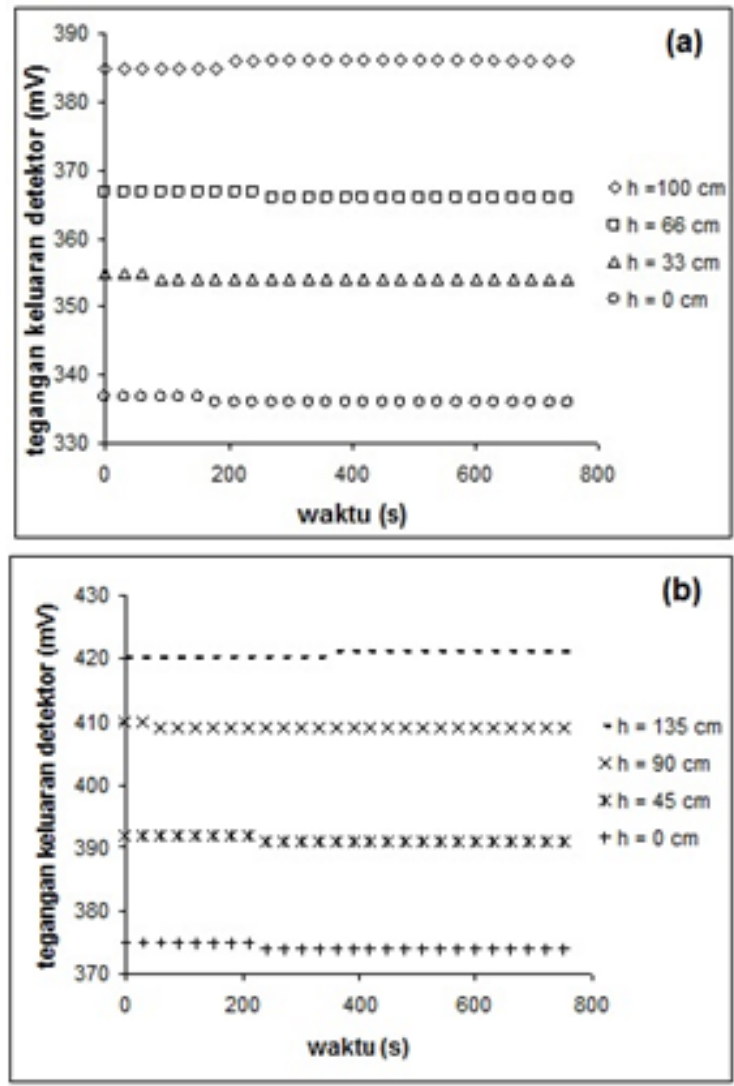

Gambar 7. Grafik hasil uji stabilitas sensor untuk (a) PPR 1 dan (b) PPR 2.

Tabel 1. Karakteristik sensor ketinggian air menggunakan concentric bundle probe.

\begin{tabular}{lcccc}
\hline \multirow{2}{*}{ Parameter } & \multicolumn{3}{c}{ Nilai Parameter } & \multicolumn{2}{c}{ PPR 2 } \\
\cline { 2 - 5 } & \multicolumn{2}{c}{ PPR 1 } & pengosongan & pengisian \\
\cline { 2 - 5 } & pengosongan & pengisian & 150 & 150 \\
\hline Jangkauan $(\mathrm{cm})$ & 130 & $0-100$ & $0-135$ & $0-135$ \\
Daerah linier (cm) & $0-100$ & 0,35 & 0,34 & 0,29 \\
Sensitivitas (mV/cm) & 0,43 & 1,1 & 1,2 & 1,4 \\
Resolusi (cm) & 0,9 & & & \\
\hline
\end{tabular}




\section{Kesimpulan}

Concentric bundle probe dapat diaplikasikan sebagai sensor ketinggian air dengan berbasis pada sensor pergeseran. Prinsip kerja sensor dengan memanfaatkan perubahan tekanan hidrostatis akibat perubahan ketinggian zat cair untuk menggeser reflektor. Hasil eksprimen memperlihatkan penggunaan membran satu lapis sebagai perangkat pergeseran reflektor menghasilkan kinerja sensor yang terbaik dengan resolusi dan daerah kerja sensor masing-masing sebesar $0,9 \mathrm{~cm}$ dan $100 \mathrm{~cm}$.

\section{Daftar Rujukan}

[1] M. Lomer, J. Arrue, C. Jauregui, P. Aiestaran, J. Zubia, J.M. Lopez-Higuera, Lateral polishing of bends in plastic optical fibres applied to a multipoint liquid-level measurement sensor, Sens. Actuators A 137 (2007) 68-73.

[2] Pekka Raatikainen, Ivan Kassamakov, Roumen Kakanakov, Mauri Luukkala, Fiber-optic liquid-level sensor, Sens. Actuators A 58 (1997) 93-97.

[3] Chengning Yang, Shiping Chen, Guoguang Yang, Fiber optical liquid level sensor under cryogenic environment, Sens. Actuators A 94 (2001) 69-75.

[4] Hossein Golnabi, Design and operation of a fiber optic sensor for liquid level detection, Opt. Lasers Eng. 41 (2004) 801-812.

[5] Kyung-Rak Sohn, Joon-Hwan Shim, Liquid-level monitoring sensor systems using fiber Bragg grating embedded in cantilever, Sens. Actuators A 152 (2009) 248-251.

[6] DONG XiaoWei, LIU WenKai \& ZHAO RuiFeng, Liquid-level sensor based on tapered chirped fiber grating, Sci. China Tech. Sci. 56 ( 2) (2013) 471-474.

[7] Jian-Neng Wang, Ching-Ying Luo, Long-period fiber grating sensors for the measurement of liquid level and fluid-flow velocity, Sensors 12 (2012) 4578-4593.

[8] Samian, G.Y.Y. Yhosep, A.H. Zaidan, Herlik Wibowo, Gasoline level sensor based on displacement sensor using fiber coupler, Measurement 58 (2014) 342-348.

[9] M. Yasin, S. W. Harun, H. A. Abdul-Rashid, Kusminarto, Karyono, A. H. Zaidan, H. Ahmad, Performance of optical displacement sensor using a pair type bundled fiber from a theoretical and experimental perspective, J. Optoelectron. Adv. Mater. - Rapid Commun.1 (11) (2007) 549 - 553. 